\title{
NGHIÊN CỬU ÚNG DỤNG CÔNG NGHỆ GOOGLE EARTH ENGINE ĐÁNH GIÁ SỰ THAY ĐỔI THẢM THỤ̉C VẠTT THEO KHÔNG GIAN VÀ THỜI GIAN Ở BẾN TRE TRONG MÙA KHÔ GIAI ĐOẠN 2016-2020
}

\author{
Trần Anh Phương1, Trần Mạnh Cường1', Phạm Văn Chiến², Lê Vũ Việt Phong ${ }^{3}$
}

Tóm tắt: Trong thời gian gần đây, công nghệ điện toán đám mây cho phép nguời dùng triết xuất, xủ lý, lư trũ dĩ liệu viễn thám trên đám mây đã góp phần làm giảm đáng kể tài nguyên máy tính cũng nhu thời gian tính toán và xử lý dũ liệu. Nghiên cứu này ứng dụng công cu điện toán đám mây Google Earth Engine để đánh giá sụ thay đổi thảm thục vật theo không gian và thời gian, đặc biệt trong các thời kỳ hạn hán trên địa bàn tỉnh Bến Tre trong mùa khô giai đoạn 2016-2020 sủ dụng chỉ số khác biệt thực vật (NDVI) tính toán tù ảnh vệ tinh Sentinel và Landsat. Kết quả tính toán cho thấy chi số NDVI tính tù ảnh Sentinel và Landsat có độ tin cậy tuơng đối cao và có mối quan hệ chặt chẽ với các thời kỳ khô hạn. NDVI thấp hơn ở các tháng cuối mùa khô của các năm hạn hán (2016 và 2020). Theo không gian, trong khi chi số NDVI ở vùng trồng lúa giảm đi rõ rệt trong nhũng năm hạn thì ở vùng trồng dừ chỉ số này không thay đổi đáng kể trong nhũng năm hạn. Kết quả của nghiên cứu này có thể được sủ dụng để đánh giá ảnh hưởng của hạn hán đến sản xuất nông nghiệp ở Bến Tre.

Từ khóa: Thảm thục vật, Google Earth Engine, Viễn thám, Hạn hán.

Ban Biên tập nhận bài: 06/4/2020 Ngày phản biện xong: 22/5/2020 ～Ngày đăng bài: 25/5/2020

\section{Giới thiệu}

Trong những năm gần đây, công nghệ viễn thám đã được sử dụng ngày càng rộng rãi trong nghiên cứu hạn hán và ảnh hưởng của hạn hán đến thảm thực vật. Chẳng hạn, [1] đã sử dụng chỉ số khác biệt thực vật chuẩn hoá NDVI (Normalized Diference Vegetation Index) để theo dõi, đánh giá hạn hán ở các bang miền trung nước Mỹ trong giai đoạn 1989-2000. [2] sử dụng số liệu quan trắc từ vệ tinh AVHRR (Advanced Very High Resolution Radiometer) để đánh giá mối quan hệ giữa nhiệt độ bề mặt đất và chỉ số NDVI trong các điều kiện độ ẩm và khí hậu/chế độ bức xạ khác nhau. [3] đã xây dựng chỉ số hạn hán tích hợp bao gồm các chỉ số thực vật $(V C I)$, chỉ số nhiệt độ (từ ảnh vệ tinh MODIS) và chỉ số mưa (từ mưa vệ tinh TRMM) phục vụ theo dõi hạn hán ở tỉnh Shandong, Trung Quốc. Ở lưu vực sông Mê Công, [4] sử dụng số liệu mưa vệ tinh CHIRPS để phân tích tình hình hạn hán ở vùng hạ lưu lưu vực sông Mê Công. [5] đã xây dựng một chỉ số hạn tổng hợp cho ĐBSCL từ số liệu tỉ lệ giữa bốc hơi thực tế và bốc hơi tiềm năng, chỉ số nhiệt độ bề mặt và chỉ số NDVI tính toán từ ảnh vệ tinh MODIS. [6] sử dụng số liệu nhiệt độ bề mặt và chỉ số NDVI từ ảnh vệ tinh MODIS để xác định chỉ số nhiệt độ khô hạn thực vật (Temperature Vegetation Dryness Index, TVDI), phục vụ đánh giá diễn biến hạn nông nghiệp trong các mùa khô giai đoạn 2001 - 2010.

${ }^{1}$ Viện Khoa học tài nguyên nuớc

${ }^{2}$ Truòng Đại hoc Thuỷ lợ

${ }^{3}$ Truò̀ng Đại học khoa học tự nhiên, Đại học quốc gia Hà Nội

Email:phuongtran.monre@gmail.com 
Số liệu độ ẩm quan trắc từ vệ tinh AMSR-E và số liệu mưa TRMM cũng được thu thập để đánh giá mối quan hệ giữa chỉ số hạn hán TVDI với lượng mưa mưa và độ ẩm đất. Có thể nói các nghiên cứu trong và ngoài nước đều chỉ ra rằng có mối liên hệ chặt chẽ giữa hạn hán và sự thay đổi của thảm thực vật. Tuy nhiên các nghiên cứu này chủ yếu sử dụng số liệu từ một nguồn ảnh vệ tinh để đánh giá sự biến đổi của thảm thực vật. Chưa có nhiều nghiên cứu kết hợp các nguồn ảnh vệ tinh khác nhau để so sánh, đánh giá độ tin cậy của các nguồn ảnh. Hơn nữa, các nghiên cứu về hạn hán chủ yếu sử dụng các loại ảnh có độ phân giải không gian thấp như MODIS, do đó không đánh giá chi tiết được sự biến đổi theo không gian của thảm thực vật. Do đó, việc nghiên cứu đánh giá sự biến đổi của thảm thực vật sử dụng tổ hợp các nguồn ảnh vệ tinh khác nhau có độ phân giải cao là rất cần thiết.

Gần đây, công nghệ điện toán đám mây (Computing cloud) đã phát triển và trở nên phổ biến, cho phép người dùng thực hiện công việc của mình trên đám mây, nhằm tiết kiệm thời gian tính toán, xử lý số liệu và dung lượng bộ nhớ. Trong các công nghệ điện toán đám mây được phát triển, công cụ Google Earth Engine (GEE) của Google là một trong các công cụ lưu trữ và tính toán dữ liệu viễn thám và thông tin địa lý (GIS) được sử dụng rộng rãi nhất. Công cụ cho phép sử dụng, tính toán và triết xuất dữ liệu cho khu vực nghiên cứu từ bộ cơ sở dữ liệu ảnh vệ tinh được lưu trữ trên hệ thống máy chủ của Google, do vậy tiết kiệm được rất nhiều tài nguyên máy tính cũng như thời gian tính toán so với các phương pháp tính toán truyền thống. Tuy nhiên, ở Việt Nam hiện chưa có nhiều nghiên cứu sử dụng công cụ này. Vì vậy việc nghiên cứu công cụ này phục vụ đánh giá biến động của các đối tượng trên bề mặt đất là rất cần thiết.

Đồng bằng sông Cửu Long (ĐBSCL) là một vùng đồng bằng trù phú, rộng lớn nhất nước ta với diện tích $39.400 \mathrm{~km}^{2}$ (12\% diện tích cả nước) nằm ở hạ nguồn của sông Mê Công với một mạng lưới sông ngòi dày đặc. Đây là vùng sản xuất nông nghiệp lớn nhất cả nước, đóng góp
$50 \%$ sản lượng lúa, 65\% sản lượng nuôi trồng thuỷ vản và $70 \%$ các loại cây ăn trái của cả nước (Nghị quyết 120). Tuy nhiên, trong những năm gần đây, ĐBSCL đang đứng trước những thách thức to lớn, đặc biệt là tình trạng hạn mặn, thiếu nước ngọt vào mùa khô dưới tác động của biến đổi khí hậu cũng như các hoạt động khai thác tài nguyên nước của các quốc gia thượng nguồn sông Mê Công. Chỉ trong vòng 5 năm trở lại đây ĐBSCL đã phải gánh chịu 2 đợt hạn mặn kỷ lục là 2015-2016 và 2019-2020, gây thiệt hại lớn về sản xuất và sinh hoạt của nhân dân trong vùng. Bến Tre là một trong số những tỉnh chịu thiệt hại nặng nề nhất của hạn hán và xâm nhập mặn ở ĐBSCL. Trong đợt hạn mặn 2015-2016, sản lượng lúa đông xuân của Bến Tre chỉ đạt 800 tấn, bằng 1\% cùng kỳ năm 2014-2015 do gần 15.000 ha lúa của tỉnh bị mất trắng vì nhiễm mặn [7]. Trong đợt hạn mặn 2019-2020 đang diễn ra, Bến Tre hiện có trên 5.200 ha diện tích lúa bị thiệt hại; khoảng 20.000 ha cây ăn trái, 72.000 ha dừa và hơn 1.000 ha cây giống có nguy cơ bị ảnh hưởng; 722 ha diện tích nuôi tôm càng xanh bị ảnh hưởng. Vì vậy việc đánh giá sự biến động của thảm thực vật theo không gian và thời gian, đặc biệt trong các thời kỳ khô hạn là rất cần thiết, làm tiền đề cho việc đánh giá ảnh hưởng của hạn hán đề sản xuất nông nghiệp trên địa bàn tỉnh Bến Tre nói riêng và ĐBSCL nói chung.

Mục tiêu của nghiên cứu này là ứng dụng công nghệ GEE để truy cập, xử lý và đánh giá sự thay đổi của thảm thực vật theo không gian và thời gian ở Bến Tre trong giai đoạn 20162020 sử dụng chỉ số NDVI được tính từ các nguồn ảnh vệ tinh có độ phân giải cao bao gồm Landsat (độ phân giải $30 \mathrm{~m}$ ) và Sentinel (độ phân giải $10 \mathrm{~m}$ ). Đồng thời, nghiên cứu cũng đánh giá ảnh hưởng của hạn hán đến sự thay đổi thảm thực vật thông qua phân tích, đánh giá chỉ số NDVI trong các thời kỳ khô hạn.

\section{Số liệu và Phương pháp nghiên cứu \\ 2.1 Giới thiệu khu vục nghiên cứu}

Bến Tre là một tỉnh thuộc vùng ĐBSCL có diện tích tự nhiên là $2.360 \mathrm{~km}^{2}$ hình thành do quá trình bồi tụ phù sa của sông Tiền, sông Ba Lai, sông Hàm Luông, sông Cổ Chiên. Tổng dân số 
toàn tỉnh vào khoảng 1.262.206 người cư trú trên 8 huyện và 1 thành phố (Hình 1$)$. Về điều kiện tự nhiên, Bến Tre có địa hình bằng phẳng (độ cao trung bình từ 1 đến $2 \mathrm{~m}$ so với mực nước biển), rải rác những giồng cát xen kẽ với ruộng, vườn, không có rừng cây lớn, chỉ có một số rừng chồi và những dải rừng ngập mặn ở ven biển và các cửa sông. Bến Tre có hệ thống kênh rạch chằng chịt khoảng $6.000 \mathrm{~km}$ đan vào nhau, tạo thành một lợi thế trong phát triển giao thông thuỷ, hệ thống thuỷ lợi, phát triển kinh tế biển, kinh tế vườn, trao đồi hàng hoá với các tỉnh lân cận. Về điều kiện khí tượng thuỷ văn, Bến Tre có tổng lượng mưa trong khoảng $1.250-1.500 \mathrm{~mm}$ chủ yếu tập trung vào mùa mưa từ tháng 5 đến tháng 10. Một lượng lớn nước cấp cho Bến Tre được chảy về từ hệ thống Mê Công. Vào mùa khô (từ tháng 11 năm trước đến tháng 4 năm sau) lượng nước từ thượng lưu về ít, lượng mưa thấp, xâm nhập mặn xâm nhập vào sâu bên trong nội địa gây khó khăn cho sinh hoạt và sản xuất nông nghiệp. Trong các đợt hạn mặn 2015-1016 và 2019-2020, Bến Tre là một trong số những tỉnh ảnh hưởng nặng nề nhất vùng ĐBSCL.
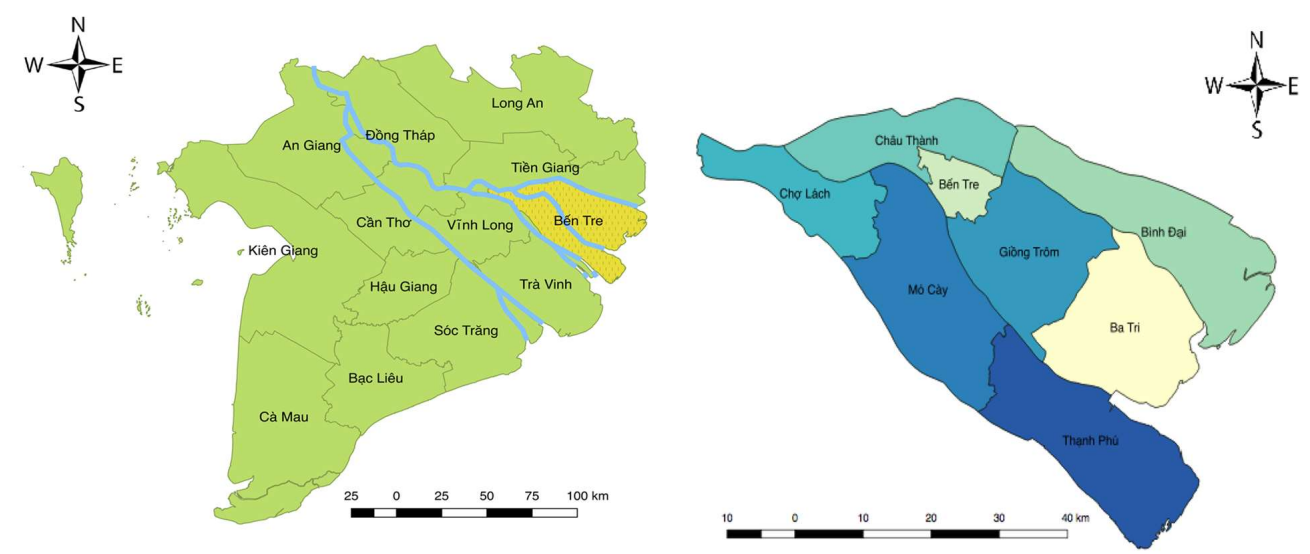

Hình 1. Vị trí tỉnh Bến Tre trong vùng Đồng bằng sông Cưu Long và bản đồ hành chính tỉnh Bến Tre

\subsection{Chỉ số khác biệt thụ̂c vật NDVI}

Chỉ số khác biệt thực vật NDVI được sử dụng trong nghiên cứu này để đánh giá biến động của thảm thực vật và mối liên hệ của nó với các thời kỳ khô hạn trên địa bàn tỉnh Bến Tre trong giai đoạn 2016-2020. Chỉ số này được tính theo công thức sau:

$$
\mathrm{NDVI}=\frac{N I R-R}{N I R+R e d}
$$

Trong đó Red và NIR đại diện cho độ phản xạ ở vùng ánh sáng đỏ (nhìn thấy) và vùng ánh sáng cận hồng ngoại. Lý do NDVI nhạy với sự thay đổi của thảm thực vật là do thực vật hấp thụ bức xạ ở vùng bước sóng màu đỏ và do đó có độ phản xạ thấp với bước sóng màu đỏ. Đồng thời, độ phản xạ của thực vật cao ở bước sóng cận hồng ngoại. Ngược lại, bề mặt đất trống có độ phản xạ cao hơn ở các bước sóng màu đỏ và thấp hơn ở các bước sóng cận hồng ngoại. Chỉ số NDVI biến thiên từ -1 đến 1 trong đó NDVI càng lớn thì thảm thực vật càng dày và ngược lại. Trạng thái của thảm thực vật tương ứng với các thang giá trị của chỉ số NDVI được trình bày ở Bảng 1 dưới đây.

Bảng 1. Thang phân chia chỉ số NDVI tưong ứng với trạng thái của thảm thực vật

\begin{tabular}{cl}
\hline Giá trị NDVI & \multicolumn{1}{c}{ Trạng thái thảm thực vật } \\
\hline$<0,1$ & Khu vực cằn cỗi của đá, cát, mặt nước, bê tông \\
$0,1-0,2$ & Đất đá cằn cồi, cậy bụi \\
$0,2-0,3$ & Cây bụi vầ trảng cỏ, đất nông nghiệp để trống \\
$0,3-0,6$ & Trảng cỏ, cây trồng nông nghiệp, rừng thưa \\
$>0,6$ & Rừng nhiệt đới \\
\hline
\end{tabular}




\subsection{Công cu Google Earth Engine}

Công cụ GEE được phát triển bởi Google với cơ sở dữ liệu chứa một lượng lớn dữ liệu vệ tinh về bề mặt Trái Đất trong quá khứ và hiện tại, cho phép các nhà nghiên cứu có thể theo dõi và phân tích được những thay đổi về bề mặt và môi trường của địa cầu theo không gian và thời gian. Để đẩy nhanh quá trình xử lý, GEE tích hợp công cụ lập trình sử dụng ngôn ngữ lập trình Javascript hoặc Python giúp phân tích, xử lý một khối lượng dữ liệu lớn ngay trên máy chủ của Google. Điều này cho phép thay vì phải tải xuống từng cảnh ảnh viễn thám và xử lý từng ảnh như cách làm truyền thống, người dùng có thể xây dựng các thuật toán tự động xử lý nhiều ảnh trên máy chủ của Google. Google cũng xây dựng sẵn các hàm API, hỗ trợ người dùng trong việc xử lý ảnh, phân tích biến đổi theo không gian và thời gian của các yếu tố quan tâm. Các bước xử lý dữ liệu ảnh viễn thám trên GEE trong nghiên cứu này được thể hiện trên Hình 2 và trình bày chi tiết dưới đây:

- Lựa chọn nguồn ảnh và thời gian lấy ảnh: Ở bước này nghiên cứu sẽ xác định loại ảnh cần lấy và khoảng thời gian cần lấy các cảnh ảnh viễn thám để phục vụ nghiên cứu. Trong nghiên cứu này, tất cả các ảnh Sentinel-2 và Landsat- 8 được thu thập ở thời kỳ mùa khô (từ tháng 1 đến tháng 5) trong giai đoạn 2016 - 2020 được thu thập để tính toán chỉ số NDVI. Chỉ số NDVI được tính theo công thức (1) sử dụng các Band màu đỏ và cận hồng ngoại. Đối với ảnh Sentinel-2, 2 band được sử dụng là band 4 (đỏ) và band 8 (cận hồng

$$
N D V I_{i, j}^{t}=\operatorname{Mean}\left\{\operatorname{NDVI}_{i, j}^{t, k} \text { if no } \operatorname{cloud}\left(N D V V_{i, j}^{t, k}\right)\right\}
$$

Trong đó $N D V I_{i, j}^{t}$ là chỉ số NDVI trung bình tháng của tháng thứ $\mathrm{t}(\mathrm{t}=1,2, \ldots, 5)$ tại ô lưới thứ $\mathrm{i}, \mathrm{j} . N D V I_{i, j}^{t, k}$ là chỉ số NDVI của lần đo thứ $\mathrm{k}$ của tháng thứ $\mathrm{t}(\mathrm{t}=1,2, \ldots, 5)$ tại ô lưới thứ $\mathrm{i}, \mathrm{j}$. Theo phương pháp chồng chập này, nghiên cứu chỉ sử dụng giá trị $N D V I_{i, j}^{t, k}$ tại ô lưới $\mathrm{i}, \mathrm{j}$ của lần đo thứ $\mathrm{k}$ của tháng thứ $\mathrm{t}$ để tính chỉ số NDVI trung bình tháng nếu tại ô lưới đó không bị mây che phủ tại lần đo thứ $\mathrm{k}$. Với phương pháp này số lượng các ô lưới bị mây che phủ sẽ được sẽ giảm đi đáng ngoại). Đối với ảnh Landsat-8, 2 band được sử dụng là band 4 (đỏ) và band 5 (cận hồng ngoại).

- Xác định khu vực nghiên cứu trên GEE: Ở bước này người dùng sẽ tải vùng nghiên cứu của mình lên GEE để phục vụ khoanh vùng tính toán. Trong bài báo này vùng nghiên cứu là tỉnh Bến Tre, thuộc vùng ĐBSCL.

- Lập bản đồ chỉ số NDVI cho khu vực nghiên cứu ở từng thời điểm có ảnh với độ che phủ mây nhỏ hơn 20\%: Để loại bỏ những bức ảnh không đủ chất lượng do bị mây bao phủ, nghiên cứu chọn ngưỡng bao phủ của mây là $20 \%$ sử dụng một thuật toán được xây dựng trong nghiên cứu này. Đối với các thuật toán thường được sử dụng, tî lệ mây được xét trong toàn khung hình của mỗi ảnh Landsat hoặc Sentinel. Điều này dẫn đến trong nhiều trường hợp có những bức ảnh mây nằm ngoài vùng nghiên cứu cũng vẫn bị loại do độ che phủ của mây trên toàn khung hình của ảnh lớn hơn $20 \%$. Thuật toán được phát triển trong nghiên cứu này cho phép chỉ loại bỏ một ảnh viễn thám khi độ che phủ mây trong khu vực nghiên cứu chiếm lớn hơn $20 \%$ diện tích của nó.

- Chồng chập các bản đồ chỉ số NDVI để tính chỉ số NDVI tháng: Nghiên cứu sẽ chồng chập các bản đồ NDVI trong cùng 1 tháng với nhau để thành lập bản đồ NDVI tháng. Việc chồng chập này đồng thời cũng giúp giảm thiểu ảnh hưởng của mây che phủ lên các cảnh ảnh. Theo đó các bản đồ NDVI trong cùng 1 tháng được chồng chập với nhau theo nguyên tắc như sau:

kể, giúp giảm thiểu sai số của bản đồ chỉ số NDVI.

- Tính chỉ số NDVI trung bình trên toàn khu vực nghiên cứu và phân tích biến động theo thời gian của chỉ số này: Với mỗi bản đồ NDVI tháng xác định ở bước trước, nghiên cứu sẽ tính chỉ số NDVI trung bình cho toàn khu vực nghiên cứu. Sau đó, biến đổi của chỉ số NDVI trung bình toàn khu vực nghiên cứu theo thời gian và mối liên hệ của nó với các thời kỳ khô hạn sẽ được 
phân tích, đánh giá. Chỉ số NDVI trung bình tháng trên toàn khu vực nghiên cứu được tính theo công thức sau:

$$
N D V I^{t}=\frac{1}{N} \frac{1}{M} \sum_{i=1}^{N} \sum_{j=1}^{M} N D V I_{i, j}^{t}
$$

Trong đó $\mathrm{N}, \mathrm{M}$ lần lượt là số ô theo chiều ngang và dọc của khu vực nghiên cứu.

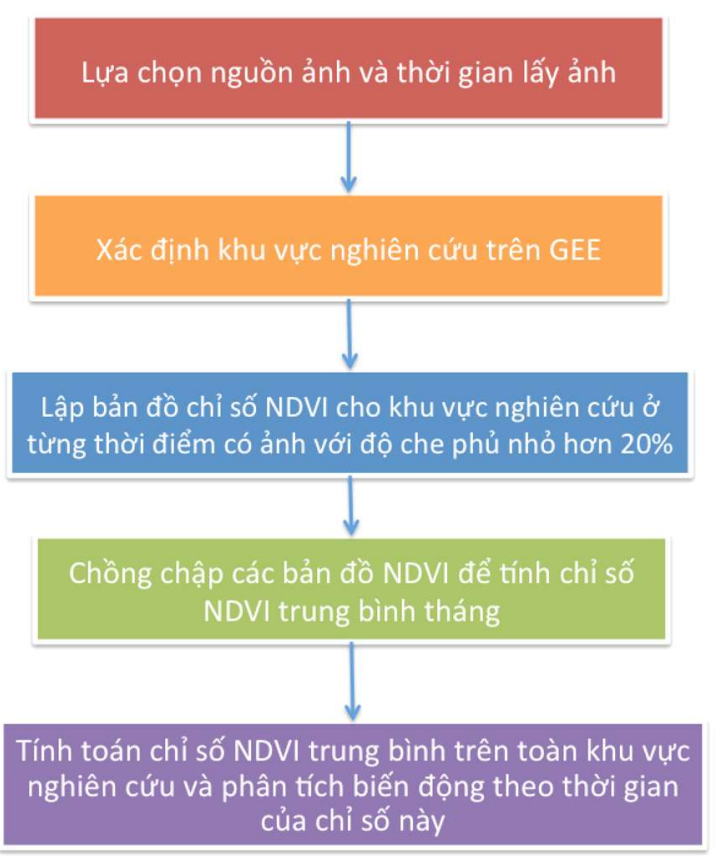

Hình 2. Các bước xử lý ảnh viễn thám để tính toán và phân tích biến động của chỉ số NDVI

\subsection{Dũ liệu sử dụng trong nghiên cúu}

Trong nghiên cứu này 2 nguồn ảnh viễn thám được thu thập bao gồm (i) dữ liệu ảnh Sentinel2 của cơ quan vũ trụ Châu Âu (ESA) và (ii) dữ liệu ảnh Landsat 8 của cơ quan vũ trụ Mỹ
(NASA). Sentinel-2 bắt đầu hoạt động từ năm 2015 với mục tiêu là chụp được các cảnh ảnh đa diện rộng, độ phân giải cao $(10 \mathrm{~m})$, với tần suất chụp toàn cầu là 5 ngày. Sentinel- 2 cho phép chụp ở 13 dải quang phổ nằm trong vùng ánh sáng nhìn thấy, cận hồng ngoại và hồng ngoại sóng ngắn. Các ảnh Sentinel-2 có thể được sử dụng để đánh giá trạng thái và sự thay đổi của thảm thực vật, thổ nhưỡng và nước. Các ảnh Sentinel-2 là miễn phí và được lưu trữ bởi nhiều đơn vị khác nhau. Nghiên cứu này sử dụng dữ liệu Sentinel-2 được lưu trữ trên GEE. Landsat8 được phóng lên vũ trụ năm 2013 là thế hệ mới nhất của hệ thống vệ tinh Landsat được phóng lên quỹ đạo lần đầu tiên năm 1972. Cho đến nay, đã có 8 thế hệ vệ tinh được phóng. Nhiệm vụ của Landsat-8 là cung cấp những thông tin quan trọng về bề mặt của Trái Đất trong nhiều lĩnh vực như quản lý năng lượng và nước, theo dõi rừng, giám sát tài nguyên môi trường, quy hoạch đô thị, khắc phục thảm họa và nông nghiệp. Dữ liệu thu nhận được sẽ được phân phối miễn phí đến người sử dụng. Ảnh Lansat-8 có độ phân giải $30 \mathrm{~m}$ và khoảng thời gian cung cấp ảnh tại một vị trí là 16 ngày với 11 dải quang phổ từ vùng ánh sáng hồng ngoại đến ánh sáng nhìn thấy. Cả hệ thống Sentinel và Landsat đều chứa ảnh ở các Band màu đỏ và hồng ngoại. Bảng 2 dưới đây cung cấp thông tin về các band này ứng với từng hệ thống vệ tinh.

Bảng 2. Các kênh ảnh được sủ dụng trong nghiên cưu

\begin{tabular}{cccc}
\hline Ảnh & Tên band & Độ phân giải & Mô tả \\
\hline Landsat-8 & B4 (RED) & 30 meters & Red \\
& B5 (NIR) & 30 meters & Near infrared \\
\multirow{2}{*}{ Sentinel-2 } & B4 (RED) & 10 meters & Red \\
& B8 (NIR) & 10 meters & Near infrared \\
\hline
\end{tabular}

\section{Kết quả}

\subsection{So sánh bản đồ chỉ số NDVI}

Trước khi đánh biến động theo không gian và thời gian của thảm thực vật, nghiên cứu tiến hành so sánh chỉ số NDVI xác định từ ảnh Sen- tinel và Landsat nhằm đánh giá độ tin cậy của chỉ số NDVI tính toán từ hai loại ảnh viễn thám này. Hình 3 dưới đây so sánh 2 bản đồ chỉ số NDVI trung bình trong tháng 1/2020 được tính từ ảnh Sentinel-2 và Landsat 8 . Hình vẽ cho 
thấy, nhìn chung cả 2 nguồn ảnh viễn thám đều cho kết quả phân phối của chỉ số NDVI theo không gian là tương tự nhau. Tuy nhiên, so với ảnh Landsat-8, hệ thống kênh rạch trên địa phận Bến Tre được thể hiện khá rõ trên ảnh Sentinel2. Điều này có thể được giải thích là do độ phân giải của ảnh Landsat-8 là $30 \mathrm{~m}$ trong khi độ phân giải của ảnh Sentinel-2 là $10 \mathrm{~m}$. Do đó, trong khi ảnh Sentinel-2 có thể phân biệt được các đối tượng có kích thước nhỏ hơn $30 \mathrm{~m}$ và lớn hơn $10 \mathrm{~m}$ thì ảnh Lansat- 8 không thể phân biệt được các đối tượng này. Hình 4 . So sánh giữa chỉ số NDVI tính từ ảnh Landsat- 8 và ảnh Sentinel-2 sử dụng hai chỉ số là hệ số tương quan (r) và sai số quân phương (RMSE) như sau:

$$
\begin{gathered}
r=\frac{\sum_{t=1}^{T}\left(N D V I_{\text {Landsat }}^{t}-\overline{N D V I_{\text {Landsat }}}\right)\left(N D V I_{\text {Sentinel }}^{t}-\overline{N D V I_{\text {Sentinel }}}\right)}{\sqrt{\sum_{t=1}^{T}\left(N D V I_{\text {Landsat }}^{t}-\overline{N D V I_{\text {Landsat }}}\right)^{2}} \sqrt{\sum_{t=1}^{T}\left(N D V I_{\text {Sentinel }}^{t}-\overline{N D V I_{\text {Sentinel }}}\right)^{2}}} \\
R M S E=\frac{1}{T} \sqrt{\left(N D V I_{\text {Landsat }}^{t}-N D V I_{\text {Sentinel }}^{t}\right)^{2}}
\end{gathered}
$$

Trong đó T là tổng số tháng có chỉ số NDVI. Ký hiệu “ _ ” là ký hiệu đại diện cho giá trị trung bình. Kết quả tính toán cho thấy ảnh Sentinel và Landsat cho chỉ số NDVI khá tương đồng nhau. Hệ số tương quan của chỉ số NDVI tính từ hai nguồn ảnh tương đối cao $(0,88)$ và sai số quân phương tương đối nhỏ $(0,03)$. Điều này cho thấy chỉ số NDVI thu được từ cả hai loại ảnh có độ tin cậy cao, có thể sử dụng để đánh giá sự biến đổi

theo không gian và thời gian của thực vật. Tuy nhiên, giá trị NDVI từ ảnh Sentinel thiên lớn hơn một chút so với từ ảnh Landsat. Sự khác biệt này có thể lý giải bởi thông thường tỉ lệ mây che phủ của ảnh Sentinel nhỏ hơn của ảnh Landsat. Kết quả là số ô lưới thực vật (có chỉ số NDVI cao) ở ảnh Sentinel có nhiều hơn ở ảnh Landsat. Do đó, giá trị NDVI tương ứng với ảnh Sentinel lớn hơn ảnh Landsat.
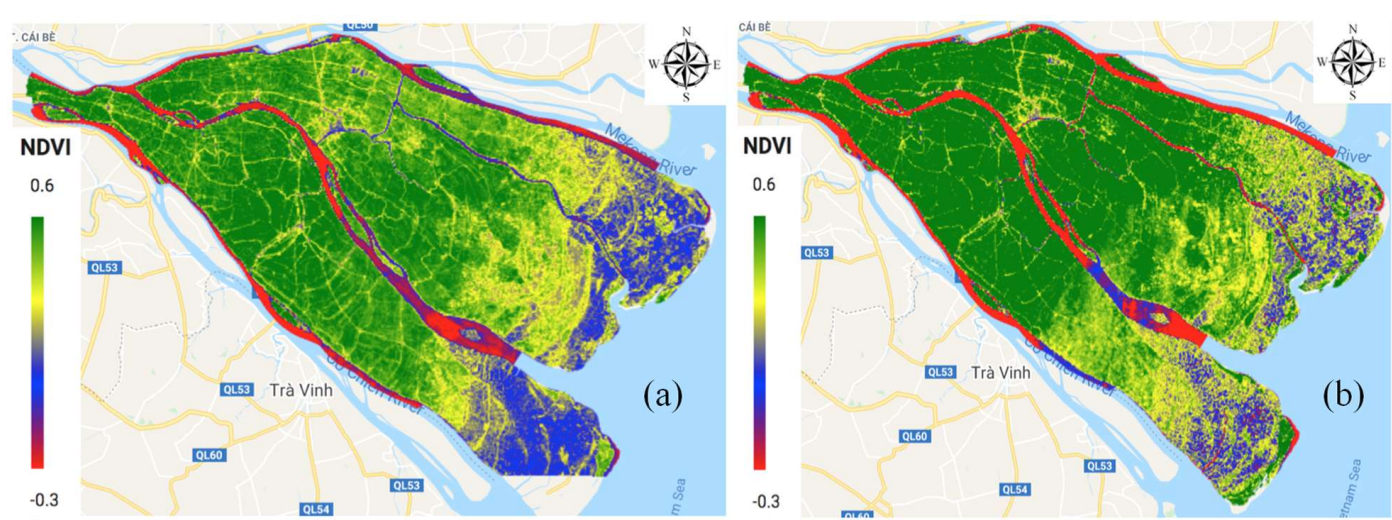

Hình 3. Bản đồ chi số NDVI cho tháng 1/20200 (Màu càng xanh thì chỉ số NDVI càng lớn, ngược lại màu càng màu đỏ thì chỉ số NDVI càng nhỏ): (a) Ảnh Sentinel-2; (b) Ảnh Landsat-8

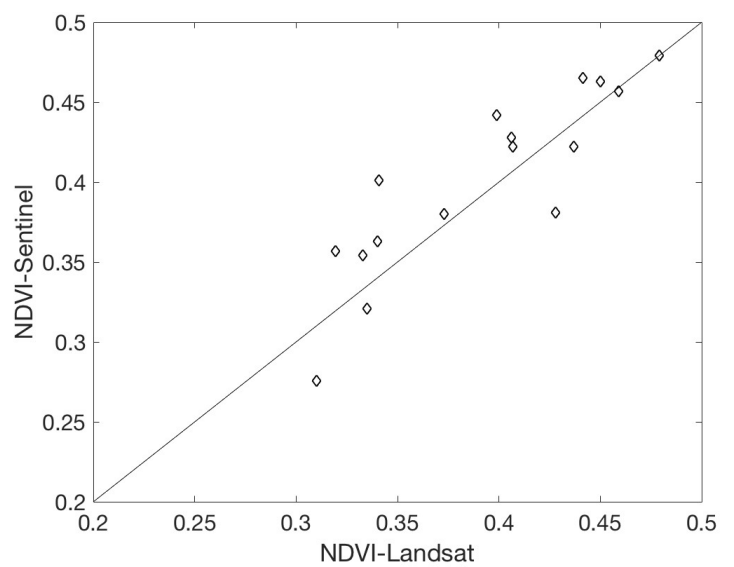

Hình 4. So sánh giũa chỉ số NDVI tính tù ảnh Landsat-8 và ảnh Sentinel-2 
3.2. Đánh giá sụ biến đổi của chỉ số NDVI theo không - thời gian và mối liên hệ với các thời kỳ khô hạn

3.2.1. Sự biến đổi của chỉ số NDVI theo không gian

Hình 5 trình bày bản đồ chỉ số NDVI tính từ ảnh Sentinel- 2 của tháng $3 / 2016$ và $3 / 2018$. Cả 2 bản đồ đều cho thấy giá trị NDVI tương đối thấp (thể hiện bởi màu đỏ và màu xanh) ở vùng ven biển và trên hệ thống sông (đại diện cho các vùng nuôi trồng thuỷ sản hoặc các ao hồ, có chứa nước với có chỉ số NDVI thấp). Trong khi đó, ở khu vực phía tây, đặc biệt là khu vực giữa của Bến Tre chỉ số NDVI cao hơn rất nhiều do đây là khu vực trồng lúa và cây ăn trái.

Ảnh hưởng của hạn hán lên biến đổi theo không gian của chỉ số NDVI trên địa bàn tỉnh

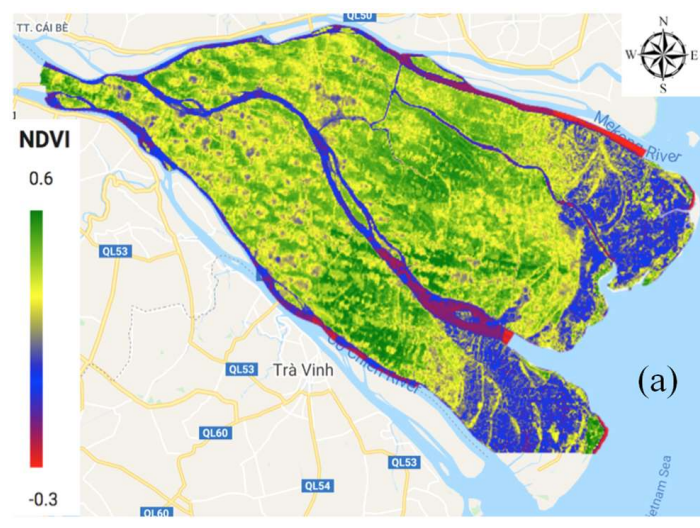

Hình 5. So sánh bản đồ chỉ số NDVI:
Bến Tre tương đối rõ qua việc so sánh bản đồ NDVI vào tháng $3 / 2016$ và $3 / 2018$. Ở cả 2 thời điểm, vùng có chỉ số NDVI cao và không biến động theo thời gian tập trung ở vùng giữa của tỉnh thuộc địa phận các huyện Giồng Trôm và Mỏ Cày. Đây là các vùng trồng dừa lớn của Bến Tre nên ảnh hưởng của hạn hán không rõ rệt do sức chống chịu với hạn hán của cây dừa tương đối tốt. Ngược lại, ở khu vực phía tây của tỉnh (thuộc các huyện Châu Thành và chợ Lách), chỉ số NDVI vào tháng 3/2018 lớn hơn nhiều vào tháng 3/2016 đo đây là khu vực trồng lúa tương đối lớn. Do ảnh hưởng của hạn hán, diện tích trồng lúa vào tháng $3 / 2016$ giảm đi đáng kể so với tháng 3/2018 dẫn đến chỉ số NDVI vào tháng 3/2016 nhỏ hơn so với tháng 3/2018.

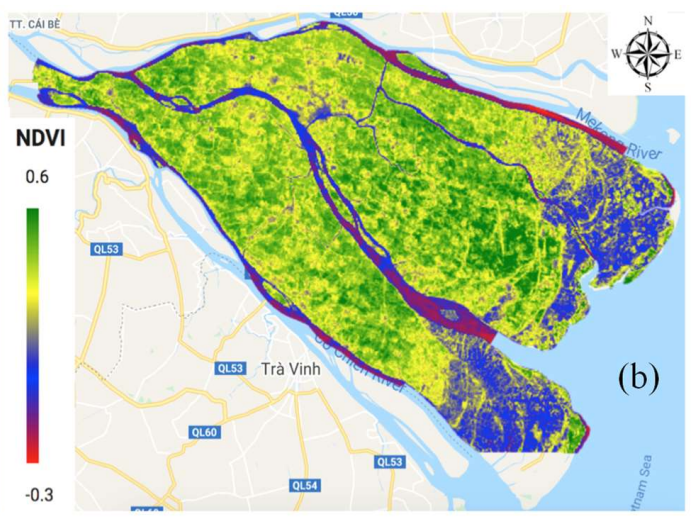

\section{(a) Tháng 3/2016 và (b) Tháng 3/2018}

lúa đông xuân đã thu hoạch xong, lúa mùa đang ở giai đoạn gieo xạ hoặc đâm trồi nên chỉ số NDVI tương đối thấp.

Hình 6 cũng thể hiện tương đối rõ ảnh hưởng của các thời kỳ khô hạn đến lớp thảm phủ nói chung và sản xuất nông nghiệp nói riêng. Cụ thể, 2 năm hạn hán trong giai đoạn 2016-2020 là 2016 và 2020 có chỉ số NDVI vào tháng 5/2016 và vào 4/2020 là thấp nhất trong các năm. Trong khi đó chỉ số NDVI trong các tháng từ tháng 1 đến tháng 3 của các năm này không thể hiện xu thế rõ ràng. Chỉ số NDVI của các năm 2016 và 2020 trong các tháng từ 1 đến 3 còn cao hơn một số năm khác. Điều này chứng tỏ ảnh hưởng của hạn hán lên thảm thực vật chỉ thể hiện rõ xu thế ở các tháng cuối mùa kiệt do lúc này cây lúa mới 
hết khả năng chống chịu với hạn hán. Kết quả tính toán cũng cho thấy chỉ số NDVI tương ứng với mùa khô năm 2019 lớn hơn rõ rệt so với các năm khác chứng tỏ trong giai đoạn 2016-2020 do đây là năm có mùa khô tương đối nhiều nước so với các năm khác.

Kết quả so sánh chỉ số NDVI tính toán từ ảnh Sentinel-2 và Landsat- 8 trên Hình 6 cho thấy xu thế biến động theo thời gian của chỉ số NDVI được tính từ 2 nguồn ảnh này là tương tự nhau. Điều này chứng tỏ độ tin cậy của chỉ số NDVI tính từ 2 nguồn ảnh tương đối cao, đủ để đánh

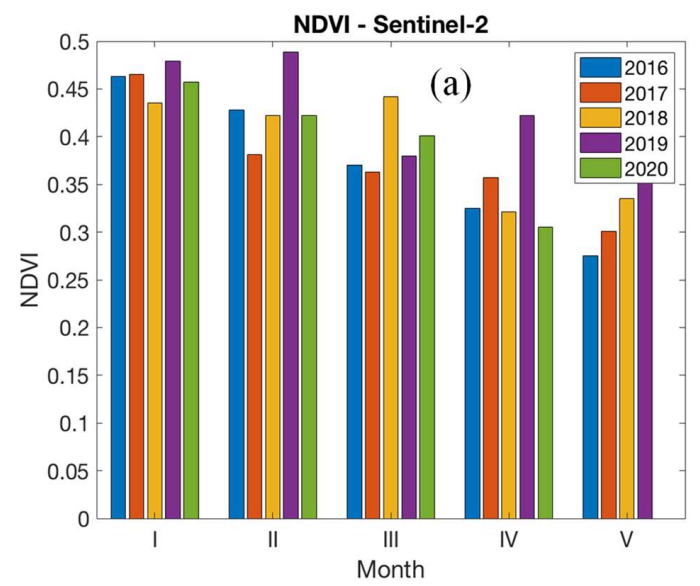

giá sự biến động theo thời gian của chỉ số NDVI. Tuy nhiên, do thời gian quay lại của vệ tinh Landsat là 16 ngày nên mỗi tháng chỉ có tối đa 2 ảnh Landsat. Do đó, nếu trong một số tháng các ảnh này không đáp ứng đủ chất lượng để tính chỉ số NDVI thì các tháng đó sẽ không có chỉ số NDVI như chỉ ra ở Hình 6b. Ngược lại, do chu kỳ lặp của ảnh Sentinel-2 là 5 ngày nên số ảnh trong 1 tháng nhiều hơn, và do đó có thể lựa chọn được các ảnh có đủ chất lượng để tính chỉ số NDVI cho từng tháng trong giai đoạn 20162020.

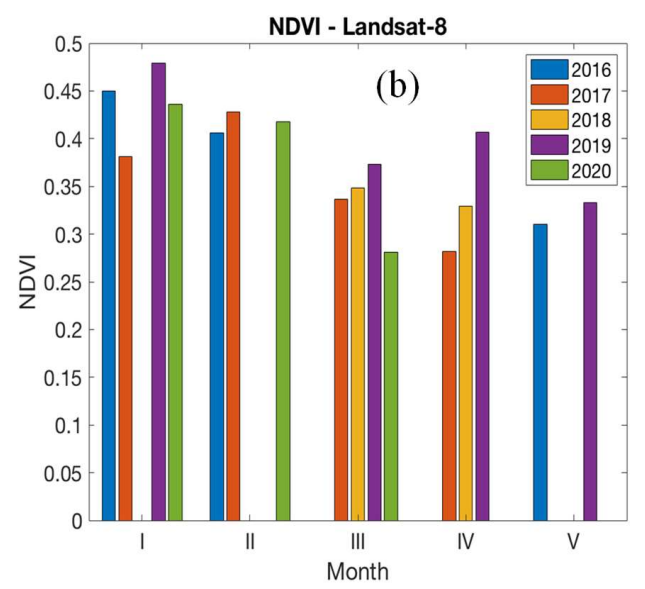

Hình 6. Biến động của chỉ số NDVI trung bình toàn tỉnh Bến Tre tù tháng 1 đến tháng 5 trong giai đoạn 2016-2020: (a) Chỉ số NDVI được tính tù ảnh Sentinel-2; (b) Chỉ số NDVI được tính tù ảnh Landsat-8

\section{Kết luận}

Nghiên cứu này đã ứng công nghệ GEE để đánh giá biến động của thảm thực vật theo không gian và thời gian và mối liên hệ của nó với các thời kỳ khô hạn ở Bến Tre trong giai đoạn 20162020, làm tiền đề cho việc đánh giá ảnh hưởng của hạn hán đến sản xuất nông nghiệp ở Bến Tre nói riêng và $\mathrm{DBSCL}$ nói chung. Biến động của thảm thực vật được xem xét thông qua chỉ số khác biệt thực vật NDVI được tính từ các phổ ánh sáng màu đỏ và cận hồng ngoại từ 2 nguồn ảnh viễn thám là Landsat- 8 và Sentinel- 2 . Kết quả tính toán cho thấy ảnh viễn thám có thể đánh giá được sự phân bố theo không gian và thời gian của thảm thực vật trên địa bàn tỉnh Bến Tre, trong đó ảnh Sentinel với độ phân giải cao cho kết quả phân bố của chỉ số NDVI chi tiết hơn. Sự biến thiên của chỉ số NDVI qua các năm cho thấy có sự tương quan giữa chỉ số này với các thời kỳ khô hạn. Theo đó, trong mùa khô các năm 2016 và 2020, chỉ số NDVI vào các tháng IV và $\mathrm{V}$ thấp hơn các năm còn lại tương ứng với các năm khô hạn nhất trong giai đoạn nghiên cứu. Theo không gian, ở các năm khô hạn, trong khi chỉ số NDVI ở vùng trồng lúa giảm đáng kể trong những năm hạn hán thì ở vùng trồng dừa và các loại cây ăn quả khác chỉ số NDVI không thay đổi đáng kể do sức chịu hạn của cây lúa kém hơn các loại cây khác. Kết quả của nghiên cứu này có thể được sử dụng trong các nghiên cứu đánh giá ảnh hưởng của hạn hán đến diện tích, năng suất và sản lượng lúa và cây ăn quả.

Lời cảm ơn: Nghiên cưu này được tài trợ bởi Quỹ Phát triển khoa học và công nghệ Quốc gia (NAFOSTED) trong đề tài mã số 105.06-2017.320. 


\title{
BÀI BÁO KHOA HỌC
}

\section{Tài liệu tham khảo}

1. Tran, T.V., Tran, D.X., Myint, S.W., Latorre-Carmona, P., Ho, D.D., Tran, P.H., Dao, H.N. (2019), Assessing Spatiotemporal Drought Dynamics and Its Related Environmental Issues in the Mekong River Delta. Remote Sensing, 11 (23), 2742.

2. Karnieli, A., Agam, N., Pinker, R.T., Anderson, M., Imhoff, M.L., Gutman, G.G., Goldberg, A. (2010), Use of NDVI and land surface temperature for drought assessment: Merits and limitations. Journal of Climate, 23 (3), 618-633.

3. Du, L., Tian, Q., Yu, T., Meng, Q., Jancso, T., Udvardy, P., Huang, Y. (2013), A comprehensive drought monitoring method integrating MODIS and TRMM data. International Journal of Applied Earth Observation and Geoinformation, 23, 245-253.

4. Guo, H., Bao, A., Liu, T., Ndayisaba, F., He, D., Kurban, A., De Maeyer, P. (2017), Meteorological drought analysis in the Lower Mekong Basin using satellite-based long-term CHIRPS product. Sustainability, 9 (6), 901.

5. Tran, T.V., Tran, D.X., Myint, S.W., Latorre-Carmona, P., Ho, D.D., Tran, P.H., Dao, H.N. (2019), Assessing Spatiotemporal Drought Dynamics and Its Related Environmental Issues in the Mekong River Delta. Remote Sensing, 11 (23), 2742.

6. Son, N.T., Chen, C.F., Chen, C.R., Chang, L.Y., Minh, V.Q. (2012). Monitoring agricultural drought in the Lower Mekong Basin using MODIS NDVI and land surface temperature data. International Journal of Applied Earth Observation and Geoinformation, 18, 417-427.

7.https://bizlive.vn/thoi-su/han-han-nhiem-man-gay-thiet-hai-hon-15000-ty-dong1743196.html

\section{Application of Google Earth Engine tool to assess the spatio-temporal variations of vegetation in Ben Tre during the dry season of the 2016-2020 period}

\author{
Tran Anh Phuong', Tran Manh Cuong' ${ }^{1}$ Pham Van Chien ${ }^{2}$, Le Vu Viet Phong ${ }^{3}$ \\ ${ }^{1}$ Water Resources Institute \\ ${ }^{2}$ Thuy loi University \\ ${ }^{3}$ College of Sciences, Vietnam National University, Hanoi
}

\begin{abstract}
In recent years, cloud computing has been widely developed to store, process and analyze remote sensing data, allowing users to carry out their works in the cloud, which helps to significantly reduce computing time and save computer resources. This study employed the Google Earth Engine tool to assess the spatio-temporal variations of vegetation in Ben Tre province during the 2016-2020 dry season using Sentinel-2 and Landsat-8 images. Results showed that the NDVI index obtained by Sentinel and Landsat can reliably assess the spatial and temporal variations of vegetation and closely correlates with the dry spans in Ben Tre province. Sentinel images with a finer resolution provides the NDVI maps with more detailed temporal and spatial resolution than Landsat images. The NDVI index in April and May of the dry years (2016 and 2020) was lower than the other years. As for the spatial variation, while this index relatively small in the dry years in the rice growing region in dry years, it is still high in the coconut growing region. These results can be used to evaluate the impacts of drought on agriculture in Ben Tre Province.
\end{abstract}

Keywords: Drought, Ben Tre, Google Earth Engine, Remote sensing, Sentinel, Landsat. 